Sourabh Pawade, Pushkar Masodkar, Prof Pankaj Hedaoo/ International Journal of

Engineering Research and Applications (IJERA) ISSN: 2248-9622 $\underline{\text { www.ijera.com }}$

Vol. 1, Issue 3, pp.1080-1087

\title{
Tracking And Positioning Of Mobile Systems In Telecommunication Networks
}

\author{
Sourabh Pawade*, Pushkar Masodkar**, Prof Pankaj Hedaoo*** \\ $3^{\text {rd }}$ year, Electronics and Telecommunicaton, \\ G.H. Raisoni College of Engineering, Nagpur, India \\ $3^{\text {rd }}$ year, Electronics and Telecommunicaton, \\ G.H. Raisoni College of Engineering, Nagpur, India \\ Lecturer, Electronics and Telecommunicaton, \\ G.H. Raisoni College of Engineering, Nagpur, India
}

\begin{abstract}
Mobile positioning technology has become an important area of research, for emergency as well as for commercial services. Mobile positioning in cellular networks will provide several services such as, locating stolen mobiles, emergency calls, different billing tariffs depending on where the call is originated, and methods to predict the user movement inside a region. The evolution to location-dependent services and applications in wireless systems continues to require the development of more accurate and reliable mobile positioning technologies. The major challenge to accurate location estimation is in creating techniques that yield acceptable performance when the direct path from the transmitter to the receiver is intermittently blocked. This is the Non-Line-OfSight (NLOS) problem, and it is known to be a major source of error since it systematically causes mobile to appear farther away from the base station (BS) than it actually is, thereby increasing the positioning error.
\end{abstract}

In this paper, we present a simple method for mobile telephone tracking and positioning with high accuracy. Through this we will discuss some technology used for mobile positioning and tracking.

Keywords - Mobile Technology, Need for Geolocation, Handset Based Mobile Positioning \&Tracking, Direction based Geo-location, Location Tracking Curve method

\section{INTRODUCTION MOBILE TECHNOLOGY}

In a cellular mobile telecommunication network, the whole service area is divided into a several coverage areas having respective base stations (BS). Each BS coverage area is called a "cell." Each BS is provided with a frequency of a range between 450 to900 $\mathrm{MHz}$ more than one cell can use same frequency. Only condition is that no two adjacent cells must have same frequencies. An MTSO controls these BSs so that a subscriber can continue his call without interruption while moving between different cells. The MTSO can reduce the time required for calling a subscriber by locating the cell of the subscriber. In case of an emergency like a fire, or a patient needing first aid treatment, the mobile subscriber should be accurately located. Tracking the location of a mobile subscriber within the boundary of a cell in a mobile telecommunication network is known as "location based services".

Mobile technology includes mainly two functions. They are call fixing and hands-off process. All the BSs are sending a signal of power 25 to $30 \mathrm{w}$ to the mobile unit. When a user switches ON his mobile, it will search for the strongest signal and get connected to that BS. Then the mobile unit sends an identification signal to the BS. When he fixes a call, the BS accepts the request and sends the request to the BSC and MTSO. Then the MTSO will search where the subscriber is and connects the call. When a user moves to another cell the MTSO will change the frequency allotted to it and allots the frequency of the new BS. For both these processes GEOLOCATION of the mobile unit is essential. 


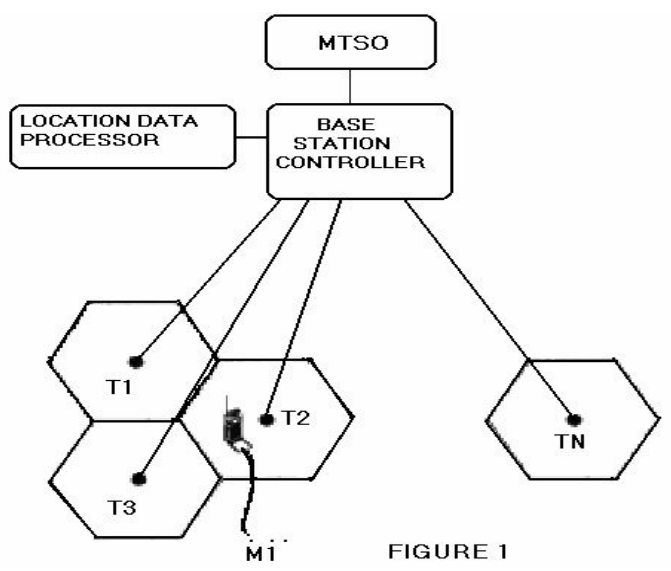

As shown in Figure 3, the mobile telecommunication network includes a several base stations (BSs) $\mathrm{T} 1$ to $\mathrm{T} \mathrm{N}$ for providing mobile telecommunication service to a mobile subscriber through a mobile telephone M1, a base station controller (BSC) for controlling the BSs $\mathrm{T} 1$ to $\mathrm{T}$ $\mathrm{N}$, and a mobile telephone switching office (MTSO) for connecting the BSC to another BTS or a PSTN (Public Switched Telephone Network).

\section{NEED FOR GEO-LOCATION}

One of the most powerful ways to personalize mobile services is based on location. The location based services, provides the subscribers very best of the service. Recent demands from new applications require positioning capabilities of mobile telephones or other devices. The ability to obtain the geo-location of the Mobile Telephone (MT) in the cellular system allows the network operators to facilitate new services to the mobile users. The most immediate motivation for the cellular system to provide MT position is enhanced in accident emergency services. The geo-location of the mobile user could provide services like-

- Emergency service for subscriber safety.

- Location sensitive billing.

- Cellular Fraud detection.

- Intelligent transport system services.

- Efficient and effective network performance and management.

i. ARCHITECTURE OF A GEOLOCATION SYSTEM
An example of geo-location system architecture [KOSO0] is shown in Figure. As we said earlier, in order to fix a call the subscriber we are calling must be located accurately. A geolocation service provider provides location information and location aware services to subscribers.

Upon a request from a subscriber for location information about an MS, the service provider will contact a location control center querying it for the coordinates of the MS. This subscriber could be a commercial subscriber desiring to track a mobile device or a PSAP trying to answer an E-911 call. The location control center will gather information required to compute the MS's location. This information could be parameters such as received signal strength, BTS ID, TOA of signals, and so on that we discuss later. Depending on past information about the MS, a set of BS's could be used to page the MS, and directly or indirectly obtain the location parameters.

These are sometimes called Geo-location base stations (GBSs). Once this information is collected, the location control center can determine the location of the mobile with certain accuracy and convey this information to the service provider. The service provider will then use this information to visually display the MS's location to the subscriber. Sometimes the subscriber could be the MS itself, in which case the messaging and architecture will be simplified, especially if the application involves self-positioning.

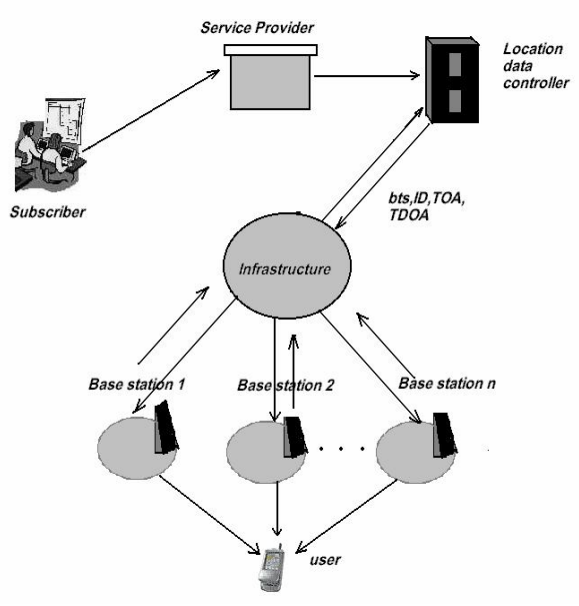


Sourabh Pawade, Pushkar Masodkar, Prof Pankaj Hedaoo/ International Journal of Engineering Research and Applications (IJERA) ISSN: 2248-9622 $\quad$ www.ijera.com

Vol. 1, Issue 3, pp.1080-1087

\section{TECHNOLOGIES USED FOR GEO- LOCATION}

\section{A. HANDSET BASED MOBILE POSITIONING} AND TRACKING

\section{1) GLOBAL POSITIONING SYSTEM (GPS)}

A mobile telephone can be located by a mobile telephone itself or through a mobile telecommunication network. To locate the mobile telephone by itself, the mobile telephone is provided with a GPS receiver to calculate its location in latitude and longitude coordinates based on the location information received from a satellite through the GPS receiver.

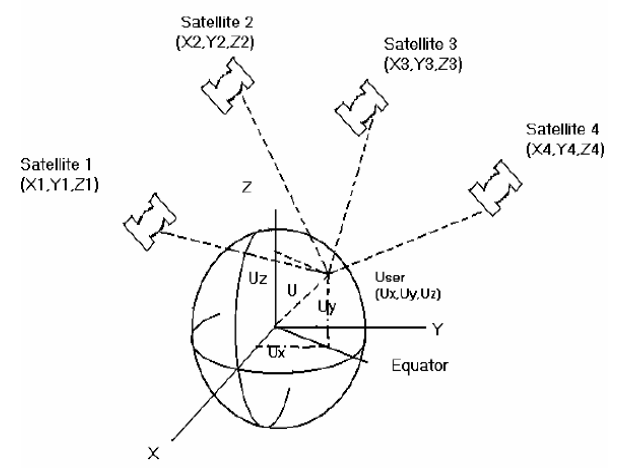

- Increases the price and the size of the mobile telephone.

- The load on the mobile telephone is increased.

- Power consumption is high.

Equations

The equations are an exception to the prescribed specifications of this template. You will need to determine whether or not your equation should be typed using either the Times New Roman or the Symbol font (please no other font). To create multileveled equations, it may be necessary to treat the equation as a graphic and insert it into the text after your paper is styled.

\section{B. DIRECTION BASED GEOLOCATION}

\section{1) ANGLE OF ARRIVAL METHOD}

As said earlier there will be transmission and reception of signals between the mobile unit and BSs. This method calculates the angle of arrival of signal receiving at the $\mathrm{BS}$. When a mobile user switches the system $\mathrm{ON}$ it receives the signal from different base stations, may be 3 or 4 or more. The angle of arrival method two or more base station for the determination. It measures the direction of signal falling on the base station and measures the angle of incidence with respect to a normal and determines the position of the system. Angle of arrival method is not an accurate method used for the mobile positioning because of its some disadvantages such as:

- The determination of the system will be in error if the angle of incidence is changed due to any obstacle like atmospheric particles or due to scattering etc.

- The accurate location cannot be determined if the mobile user is in between the BSs, that is in a straight line.It cannot be used for the indoor environments.

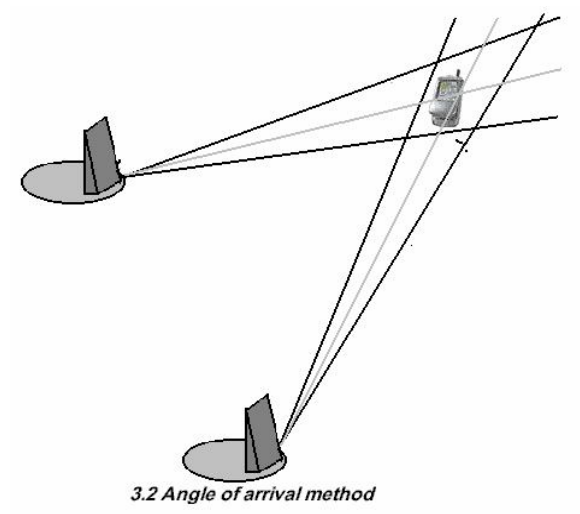

The accuracy of the method can be increased by increasing the number of the base stations used for determination. The direction based mobile positioning is not used commonly now a day. It is replaced by the distance based mobile positioning technologies.

\section{DISTANCE BASED POSITIONING}

\section{1) TIME OF ARRIVAL (TOA)}

The TOA method calculates the distance of a mobile telephone and a BS based on the TOA of a signal transmitted from the mobile telephone at the BS. It is assumed that the mobile telephone is located at the intersection point of three circles having the radius of the distances between the BSs and the mobile telephone. The distance is calculated by the following equation.

$\underset{i}{\mathrm{R}}=\mathrm{C} \tau_{\mathrm{i}=} \operatorname{sqrt}\left(\left(\mathrm{x}_{\mathrm{i}}-\mathrm{X}\right)^{2}+\left(\mathrm{y}_{\mathrm{i}}-\mathrm{Y}\right)^{2}\right)$ where,

C - Propagation speed of electromagnetic wave, 
$\tau_{\mathrm{i}}$ - propagation of time from the mobile telephone to $i$ base station,

$x_{i}, y_{i}$ - location of $i^{\text {th }}$ base station,

\section{$X, Y$ - mobile position}

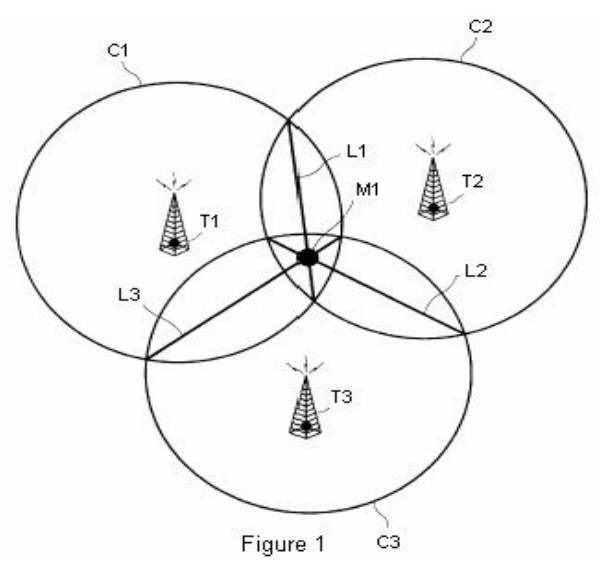

Figure3.3 illustrates a typical TOA method for locating a mobile telephone.

As shown in Figure 1, three circles C1, C2, and C3, whose radii are the distance between the mobile telephone M1 and at least three BSs T1, T2, and T3, are overlapped across an area. The mobile telephone M1 is located in the overlap area. One approach to locating the mobile telephone M1 in the overlap area 1 is to use a common chord, as shown in Figure. 2. When at least three circles C1, C2, and C3 are overlapped over an area without meeting at one point, the mobile telephone M1 is considered to exist at the intersection point of three common chords L1, L2, and L3.

The above method using the common chord is not very accurate in locating the mobile telephone except in the case where the mobile telephone is at an approximate equal distance from the selected $\mathrm{BSs}$ and in a similar propagation environment to each respective $\mathrm{BS}$.

\section{2) TIME DIFFERENCE OF ARRIVAL (TDOA)}

The TDOA method assumes that the TDOAs of a signal transmitted from the mobile telephone at the three BSs define a set of points on a hyperbola, and the mobile telephone is located at the intersection point of at least three hyperbolas.

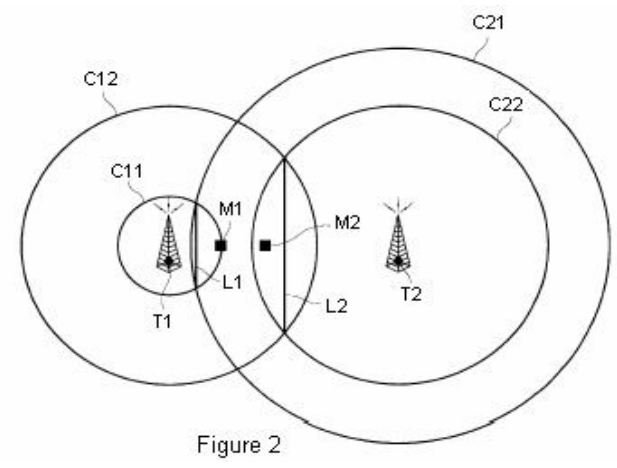

a. Sample of a Table footnote. (Table footnote)

Figure3.4, illustrates the TDOA method of locating a mobile telephone.

In the case that a first mobile telephone M1 is nearer to the first BS T1, as shown in Figure 2, the procedure will be described by a way of example. In Figure 2, two circles $\mathrm{C} 11$ and $\mathrm{C} 21$ are drawn based on the TOAs of a signal transmitted from the first mobile telephone M1 at the first and the second BSs T1 and T2. A first common chord L1 is defined by the intersection between the circles $\mathrm{C} 11$ and $\mathrm{C} 21$. But if the path between the first mobile telephone M1 and the second BS T2 is in an NLOS condition and the path between the first mobile telephone M1 and the first BS T1 is in a line-ofsight (LOS) condition, the common chord L1 is positioned far left from the actual location of the mobile telephone M1. The effect is the same in the opposite case. If the path between the first mobile telephone M1 and the second BS T2 is in the LOS condition and the path between the first mobile telephone M1 and the first BS T1 is in the NLOS condition, the common chord L1 is also far right from the actual location of the mobile telephone M1..

\section{LOCATION TRACKING CURVE METHOD}

The method proposed by us for tracking the location of a mobile telephone using curves connecting the points where circles intersect one another, the circles radii being the distances between BSs and the mobile telephone. The steps involved are: 
Sourabh Pawade, Pushkar Masodkar, Prof Pankaj Hedaoo/ International Journal of Engineering Research and Applications (IJERA) ISSN: 2248-9622 $\quad$ www.ijera.com

Vol. 1, Issue 3, pp.1080-1087

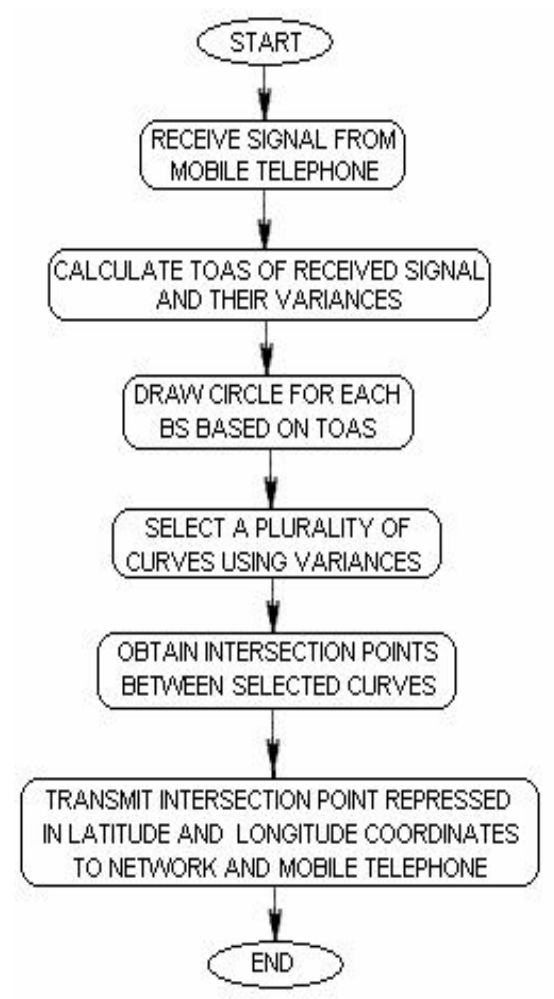

Flowchart showing the steps involved in locating a mobile telephone

\section{Description}

When a location service is requested about a specific mobile telephone by a user or a network, the location data processor draws two circles $\mathrm{C} 1$ and $\mathrm{C} 2$ with their respective centers set at BSs $\mathrm{T} 1$ and $\mathrm{T} 2$ based on the TOAs of a signal transmitted from the corresponding mobile telephone M1 or M2 to the two BSs T1 and T2 located near the mobile telephone M1 or M2. The two circles $\mathrm{C} 1$ and $\mathrm{C} 2$ define a common chord $\mathrm{L} 1$.

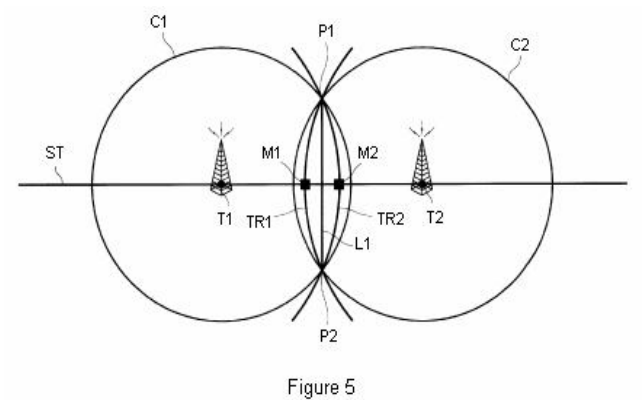

Figure3.5, illustrates a proposed method for mobile telephone location
However, if each mobile telephone M1 or M2 is placed in a different propagation environment with respect to the BSs $\mathrm{T} 1$ and $\mathrm{T} 2$, the location of the mobile telephone M1 or M2 cannot be determined by the common chord L1. Therefore, we use location tracking curves TR1 and TR2 connecting the same two intersection points $\mathrm{P} 1$ and $\mathrm{P} 2$ of the two circles $\mathrm{C} 1$ and $\mathrm{C} 2$, instead of the common chord L1.

The two curves TR1 and TR2 have their middle points intersecting the line ST, which connects the positions of the two BSs T1 and T2 and the parts of two circles $\mathrm{C} 1$ and $\mathrm{C} 2$ drawn to connect the two intersection points $\mathrm{P} 1$ and $\mathrm{P} 2$. Instead of the common chord L1, the location data processor uses the curve TR1 for the mobile telephone M1 and the curve TR2 for the mobile telephone M2. It prevents the location error caused by the multi-path fading or the NLOS path characteristics.

\section{Determination of the location tracking curve}

The BS with smaller variances should be selected to draw reference circles based on the variances.

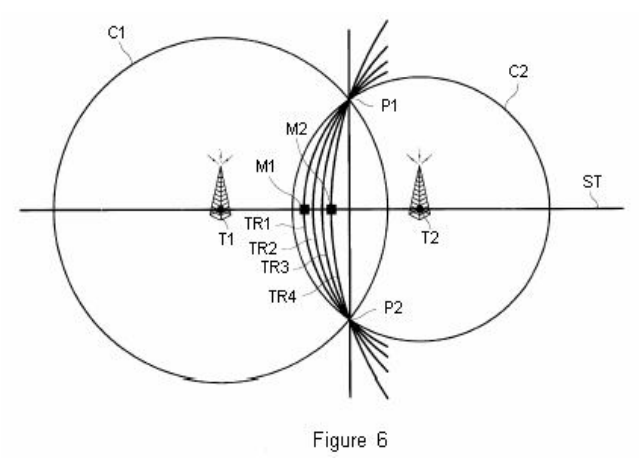

Figure 3.6, illustrates the determination location tracking curve.

From fig 3.6,assuming that the first and the second BSs T1and T2 selected for use in the location tracking are present at positions $(\mathrm{x} 1, \mathrm{y} 1)$ and $(\mathrm{x} 2, \mathrm{y} 2)$ of the two BSs $\mathrm{T} 1$ and $\mathrm{T} 2$ at their centers. The curve connects the points $\mathrm{P} 1$ and $\mathrm{P} 2$ at which the two circles $\mathrm{C} 1$ and $\mathrm{C} 2$ intersect each other. The coordinates of the intersection points $\mathrm{P} 1$ and $\mathrm{P} 2$ are $(\mathrm{xA}, \mathrm{yA})$ and $(\mathrm{xB}, \mathrm{yB})$ respectively. Since the mobile telephone is near the first BS T1 with respect to the common chord L1, the variances 


\section{Sourabh Pawade, Pushkar Masodkar, Prof Pankaj Hedaoo/ International Journal of}

Engineering Research and Applications (IJERA) ISSN: 2248-9622 $\quad$ www.ijera.com

\section{Vol. 1, Issue 3, pp.1080-1087}

of the TOAs of a signal transmitted from the mobile telephone at the first BS T1 will be larger than those of the signals at the second BS. Therefore, reference circles TR1 to TR4 are drawn with respect to the $2^{\text {nd }} \mathrm{BS} \mathrm{T} 2$ with smaller variances as shown in Fig. 6.

The coordinates of the reference circles can be obtained (using minimum variance) which has its centre on the line ST passing through(x1,y1) and $(\mathrm{x} 2, \mathrm{y} 2)$ and passes through $(\mathrm{xA}, \mathrm{yA})$ and $(\mathrm{xB}, \mathrm{yB})$. Selecting the centre of the reference circle is significant as the mobile telephone is located on the reference circle. The location data processing selects the desired curves(reference circles) with respect to the several BSs selected for location tracking. In Fig. 6, as the real location of the mobile telephone deviates farther from the circle $\mathrm{C} 2$ with the second BS T2 at its centre, the centre of a reference circle is farther from the location of the second BS T2. That is, the centre of a desired reference circle is farther from the second BS T2 in the case of a third mobile telephone M3(curve C3) than in the case of a fourth mobile telephone M4.

The location data processor sets a several reference circles based on the distances between the mobile telephone and the BS with the smaller variances(the second BS T2) In Figure 6, as an example, the first to the fourth reference circles TR1 to TR4 have radii twice, three times, four times, and five times, respectively, of that of BS $\mathrm{T} 2$, where all these points of reference circles TR1 and TR4 are located along the line ST The variances of the second BS T2 smaller than those of the first BS T1 are used as a criterion for selecting an optimal reference circle.

Therefore, the location data processor predetermines the reference variances for the first to the fourth reference circles TR1 to TR4 to be compared with respect to the second BS T1. It is assumed in the following description that $\sigma 1, \sigma 2$, and $\sigma 3$ are reference variances and $\sigma 1<\sigma 2<\sigma 3$. The location data processor compares the variances calculated by the two BSs T1 and T2 and selects the base station with smaller variances as a reference point to draw the reference circle. If the selected variances (those of the second BS T2) are $\sigma$, the location data processor compares the selected variances $\sigma$, with the preset reference variances $\sigma 1$, $\sigma 2$, and $\sigma 3$.

- If $\sigma 1<\sigma<=\sigma 2$, the curve of the TR2 is selected

- If $\sigma 2<\sigma<=\sigma 3$, the curve of the TR3 is selected.

- If $\sigma 3<\sigma$, the curve of the fourth reference circles TR4 is selected.

As we have seen, the location data processor selects the optimal curve (reference circle) for the two BSs among the several BSs, and selects another optimal circle for another BS pair, and so on.

When curves are selected for all selected BS pairs, the location data processor obtains the intersection points among the selected curves as shown in Figure 7. However, as the selected curves do not intersect at one point due to the multi-path fading or the NLOS effects, the midpoint of these intersection points is determined as the location of the mobile telephone.

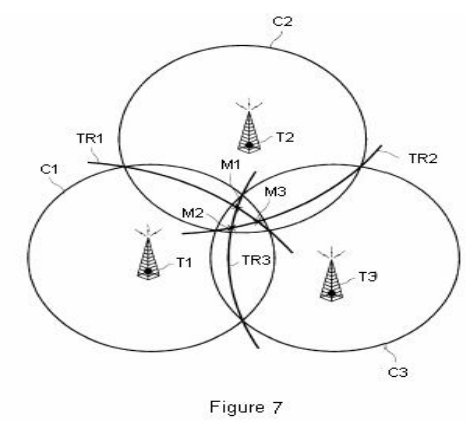

Figure 3.7, illustrates the positioning of mobile by the proposed method

As the three intersection points $\mathrm{M} 1$ (xA, yA), $\mathrm{M} 2(\mathrm{xB}, \mathrm{yB})$, and $\mathrm{M} 3(\mathrm{xC}, \mathrm{yC})$ are defined by the three curves TR1 to TR3, the location data processor considers the mobile telephone to be located at $(\mathrm{x}, \mathrm{y})$. While the three BSs are selected for the location service using the TOAs of a signal arrived at each BS from a mobile telephone has been described in the embodiment of the present invention, more BSs can be used to increase the accuracy in locating the exact position of the mobile station. If $\mathrm{N}$ intersection points are defined by location tracking curves obtained according to 
Sourabh Pawade, Pushkar Masodkar, Prof Pankaj Hedaoo/ International Journal of

Engineering Research and Applications (IJERA) ISSN: 2248-9622 $\underline{\text { www.ijera.com }}$

Vol. 1, Issue 3, pp.1080-1087

the present invention and an $\mathrm{i}^{\text {th }}$ intersection point is at $\left(x_{i}, y_{i}\right)$, coordinates $(x, y)$ indicate the location of the mobile telephone.

After the location of the mobile telephone, that is, the intersection points among the curves are obtained, the location data processor represents the intersection points in the latitude and the longitude coordinates and transmits the position coordinates to the network (BS/BSC/MSC) and the mobile telephone.

\section{CONCLUSION}

Our proposal is advantageous in that the location of a mobile telephone can be accurately tracked even in the multi-path fading and the NLOS environment, by using more accurate tracking curves connecting the intersection points among circles with the radii being the distances between corresponding BSs and the mobile telephone in a cellular mobile communication system. We have described about accurate positioning of mobile telephones, which can be used for several applications. The important considerations to be undertaken while selecting a location based technology are location accuracy, implementation cost, reliability, increasing functionality.

\section{REFERENCES}

[1] Wen Pan, Jiang Wu, Zhanjun Jiang, Yan Wang, XiaohuYou, "Mobile Position Tracking by TDOA-Doppler Hybrid Estimation in Mobile Cellular System"Communications, 2007. ICC '07. IEEE International Conference on Digital

Object Identifier:10.1109/ICC.2007.771

Publication Year: 2007 , Page(s): $4670-4673$

[2] Chin-Der Wann, Yi-Ming Chen, "Position tracking and velocity estimation for mobile positioning systems" Wireless Personal Multimedia Communications, 2002. The 5th International Symposium on Volume:

Digital

Object

Identifier:10.1109/WPMC
.2002.1088183 Publication Year: 2002 , Page(s): 310 - 314 vol.1

[3] Bekkali, A., Matsumoto M.," RFID Indoor Tracking based on Inter-tags Distance Measurement Wireless Telecommunications Symposium," Digital Object Identifier: 10.1109/WTS.2007.4563343

Publication Year: 2007.

[4] Ta Chen, Kaul, V Sultan, F Parmeswaran ,K Samtani, S Shur, D Kiernan, T Thomas, S Zimmerman, "Intelligent application persistence in tactical wireless networks" W MILITARY COMMUNICATIONS CONFERENCE, 2010 MILCOM2010 Digital Object Identifier: 10.1109/ MILCOM.2010.5680419 Publication Year: 2010 , Page(s): 195 - 200

[5] Sharp I, Kegen Y, Guo Y.J," GDOP Analysis for Positioning System Design Vehicular Technology, IEEE Transactions on Volume:58, Issue:7 Digital Object Identifier: 10.1109/TVT.2009.2017270 Publication Year: 2009 , Page(s): 3371 - 3382 Cited by: 3

[6] Muthukrishnan K, Dulman S,Langendoen, K," Towards a rapidly deployable positioning system for emergency responders Ubiquitous Positioning Indoor Navigation and Location Based Service (UPINLBS),2010 Digital Object Identifier:

10.1109/UPINLBS.2010.5654049

Publication Year: 2010 , Page(s): 1 12

[7] Vossiek, M, Wiebking L, Gulden P, Weighardt J, Hoffmann C, "Wireless local positioning-concepts, solutions, applications "Radio and Wireless Conference, 2003. RAWCON '03. Proceedings Digital Object Identifier: 10.1109/ RAWCON.2003.1227932 Publication Year: 2003 , Page(s): 219 - 224 Cited by: 12

[8] Bellini Alexandre, Cirilo, Carlos E, Prado, Antonio F, Souza, Wanderley L., Zaina, Luciana A.M, "A Service Layer for Building GSM Positioning Systems in E-Health Domain"10.1109/U-MEDIA.2011.27 
Sourabh Pawade, Pushkar Masodkar, Prof Pankaj Hedaoo/ International Journal of

Engineering Research and Applications (IJERA) ISSN: 2248-9622 $\underline{\text { www.ijera.com }}$

Vol. 1, Issue 3, pp.1080-1087

Publication Year: 2011 , Page(s): 7 12

[9] Balakrishnan D, Nayak A, Dhar P, Kaul S.," Efficient Geo-tracking and Adaptive Routing of Mobile Assets“" High Performance Computing and Communications, 2009. HPCC '09. 11th IEEE International Conference on Digital Object Identifier: 10.1109 /HPCC.2009.79 Publication Year: 2009 , Page(s): $289-296$

[10] Paschalidis I.C, Keyong Li, Dong Guo, "Landmark-based position and movement detection of wireless sensor network devices" Communication, Control, and Computing, 2008 46th Annual Allerton Conference on Digital Object Identifier: 10.1109/ ALLERTON.2008.4797528

Publication Year: 2008 , Page(s): 7 14

[11] Howell J, Frolik, J, “An Internetbased, inverse-GPS system for monitoringand tracking mobiles" Proceedings of IEEE Volume:2 Digital Object Identifier: 10.1109/ ICSENS.2002. 1037386 Publication Year: 2002 , Page(s): 1734 - 1739 vol.2

[12] "Pedestrian navigation systems and location-based services Retscher 3G Mobile Communication Technologies," 2004. 3G 2004. Fifth IEE International Conference on Digital Object Identifier:10.1049/cp: 20040696 Publication Year: 2004 , Page(s):359-363 Cited by: 1

[13] Anisetti M, Ardagna C.A., Bellandi V, Damiani, E., Reale, S., “ MapBased Location and Tracking in Multipath Outdoor Mobile Networks" Wireless Communications, IEEE Transactions on Volume:10, Issue:3 Digital Object Identifier:10.1109/TWC.2011.01181. 100025 Publication Year: 2011 , Page(s): $814-824$

[14] Thuong Le-Tien, Vu Phung, "The Routing and Tracking System for Mobile Vehicles in Large Area" Electronic Design, Test and Application, 2010. DELTA '10. Fifth IEEE International Symposium on
Digital Object Identifier: 10.1109 /DELTA.2010.38 Publication Year: 2010, Page(s): 297 - 300

[15] Romsaiyud W, Premchaisawasdi W., "Intelligent switching method using Cell-ID/GPS positioning on mobile application" ICT and Knowledge Engineering, $20097^{\text {th }}$ International Conference10.1109/ICTKE.2009 5397330 Publication Year: 2009 , Page(s): 83 - 88 